\title{
Title: The role of a social context for ICT learning and support in reducing digital inequalities for older ICT users
}

\begin{abstract}
This paper examines the key role of formal and informal social support in reducing digital inequalities by enabling the digital participation of older people. It is based primarily on research conducted on the (anonymised) project in the UK over a four year period working with over 1000 older people using mixed research methods within a participative framework. It is further informed by other studies. The rich, multi-faceted evidence reveals on the one hand the extensive learning and support needs and requirements of older users of information and communication technologies (ICTs) and, on the other, the dearth of reliable and on-going support provision. ICT learning and support in the UK relies primarily on the goodwill of friends and family and on the availability of staff and volunteers in community venues, such as public libraries. Arrangements are often ad hoc and variable in quality and reliability. In a facilitated workshop, the learning and ICT support needs of older people and their preferred forms of provision were documented and deliberated. This generated a clear set of user requirements. To meet these requirements a proposition for community-based ICT support provision has been developed and refined. The paper concludes with consideration of this proposition which offers a powerful way to reduce the widespread digital inequalities among older people.
\end{abstract}

\section{Introduction}

As more and more aspects of modern life are conducted on-line, digital participation of older people has growing relevance for many aspects of their daily lives. Digital technologies are becoming increasingly pervasive and integrated within society. Through use of the internet, they offer access not only to a vast range of information, goods and services but also to valuable opportunities to remain connected with friends and family, to make tasks of daily living easier and cheaper, and to pursue interests and hobbies enabled by ICT. Such opportunities enhance well-being and quality of life and can reduce social isolation and loneliness. However, for many older people, digital inequalities in access, in capabilities, confidence and on-going ICT support mean they are not connected to the digital world and therefore cannot capitalize on the many benefits and advantages of being online.

Some older adults are of course familiar with use of digital technologies through their use of computers in the workplace (Selwyn, 2004). But there are large numbers of older adults reported to be non-users of technology (Selwyn, 2004; Gorard and Selwyn, 2005). Recent statistics show that there over 17 million people in UK are aged 55+ (ONS, 2014a) and of the 6.7 million adults who had never used the Internet (who represent $13 \%$ of the adult population), 5.6 million (i.e. $32 \%$ of the UK older adult population) are non-users (ONS, 2014b). 
Among those older adults who are learning digital skills in later life, many find the ICT skills acquisition process which is an essential enabler of engagement with the digital world, to be highly challenging (Sandhu, Damodaran and Ramondt, 2013). The evidence reveals the magnitude of the challenge of the learning journey faced by the non-user in becoming first a novice ICT user and then a more experienced one. The types of challenges encountered are well documented (Sandhu, Damodaran and Ramondt, 2013; Damodaran, Olphert and Sandhu, 2014). They include lack of technical skills and knowledge to deal with technical problems, upgrades, disruption and distress caused by security issues (all compounded by lack of familiarity with technical jargon); physical difficulties (e.g. problems in manipulating the mouse or seeing what is on screen; and cognitive difficulties (e.g. limitations of working memory which make it difficult to remember passwords or to recall sequential steps in an operating procedure).

Research evidence gained from a multidisciplinary collaborative research project entitled (anonymised) which was funded by the UK Research Councils as part of the (anonymised) research programme will be drawn upon in this paper. Fundamental to the theme of this paper, the findings show that access to help and support is a key determinant of sustained digital inclusion i.e. the continued use of ICT in the face of age-related capability changes and rapid technological change. This paper will discuss and present research evidence relating to the role and function of social support in promoting digital engagement.

\section{Literature review}

The research literature reveals that the experiences and success of older adults in learning to use and in sustaining use of technologies are determined significantly by the availability and quality of ICT support available to them. For example, the Digital Lifestyles Media Literacy Audit Report for Ofcom (2007) revealed that asking friends, family or work colleagues (49\%) was the most widely used method for informal learning to use ICTs, followed by reading a manual (35\%); through trial and error (25\%); through the supplier or store (10\%); and finally attending a class $(6 \%)$. These findings were endorsed and extended by survey research on the Sus-IT project conducted with 715 older adults over the age of 60 showed that over half of the participants $(56.2 \%)$ stated support-related factors to be the most important thing in helping them to learn and use digital technologies successfully (Damodaran, Olphert and Sandhu, 2014). Support related factors included help and encouragement, i.e. from friends, family and tutors $(25 \%)$, the availability and provision of help in classes/drop-in centres $(22 \%)$, the quality of tutors and teaching environment (15\%), the availability of well-written guides and help information (9\%), and the availability of expert advice, i.e. technical support $(1 \%)$. Respondents reported heavy reliance on support from family members or friends both to learn and to solve ad hoc problems as they arise. Informal support particularly valued and preferred by older people seeking help with ICT issues and problems is generally provided by family and friends/peers rather than by officially designated teachers, trainers or other assigned roles. 
Several studies documenting the methods older adults have utilized to learn how to use ICTs indicate some changes over time. For example, in an interview survey study carried out in 2003 with 353 participants aged over 50, Goodman et al., (2003) found almost half of their participants had learnt to use ICTs by participating in a course (47\%); just over a quarter learnt to use ICTs within a work setting (28\%); over a tenth of older adults were self-taught (14\%); and a further tenth had learnt from a relative or friend (14\%). Also in 2003 Selwyn reported findings of a questionnaire study and a mapping exercise of 12 electoral wards and their public ICT facilities. They identified a range of computer and internet enabled sites including libraries, community centres, adult education centres, Further Education colleges, not-for-profit organizations (e.g.'telecottage centres', UK Online Centres and Learndirect Centres) which all provided training. A study conducted several years later as part of the SusIT project (Ramondt, Sandhu and Damodaran, 2013) to sample ICT learning and support provision in seven cities in the UK found that availability and the quality of provision varied greatly from venue to venue. Older people reported difficulties finding ICT training and support - especially services tailored to their needs as older ICT users. With the exception of organizations oriented specifically towards older people (such as Age UK and the University of the $3^{\text {rd }}$ Age), most ICT training for beginners catered for all age groups. Findings show that such generic teaching can be problematic for many older people. The study also reported that while face-to-face learning support was generally available in libraries, community centres and local agencies, there was little access to 'troubleshooting' assistance or to impartial advice on an on-going basis. Yet such provision has been found to be vital in helping older adults to deal with the barriers they encounter - thereby enabling them to remain connected to the digital world. Further, the limited ICT support that was found to be available tended to focus on gaining ICT skills for employment (Ramondt, Sandhu and Damodaran, 2013) rather than on promoting independence and autonomy.

It is important to emphasize that digital inequalities are not only experienced by those who have never been online, but also by some who have been users of the internet in the past but for a variety of reasons - have stopped using it. It is a common myth that 'once people are online, they stay online'. Yet various studies show that some people, who have used the internet at some point, and for some period of time, have subsequently stopped doing so (Katz J. E., Apsden, 1998; Emmanouilides and Hammond, 2000; Dutton and Blank, 2011; Young et al., 2012). The authors see this phenomenon as a potential but largely unrecognized 'fourth digital divide' (Olphert and Damodaran, 2013), i.e. it cannot be explained by a simple interpretation of lack of access, lack of skills or lack of interest or motivation, because the people in this category have formerly been users. One in ten people are reported to have given up on using computers and it has been found that the older generation are more likely to be the ones that 'give up' (Dutton and Blank, 2011). The greater challenge beyond getting people online has been recognized for some time but tends to receive little attention in published digital strategies. In 2004 the UK Digital Inclusion Panel Report (Digital Inclusion Panel, 2004) reported that "there is a real risk that in the medium to long term, significantly more citizens will migrate from being digitally engaged to being unengaged than the other way round, as their capabilities change". This risk can arise because later life is associated with sensory, physical and cognitive changes such as impaired sight and hearing and reduced 
mobility (Hawthorn, 2008). Such changes may pose problems for older individuals learning and using ICTs (Dickenson et al., 2007; Ecth, 2002; Williamson, Bow and Wale, 1997). For example, deterioration in visual function affects older ICT users' capacity to see what is on the screen ICTs (Dickenson et al., 2007; Schieber, 2003) while impaired hand dexterity can make mouse and keyboard control difficult ( Blake, 1998; Virokannas et al., 2000) and the effects of cognitive impairment among some older ICT users have been identified as barriers to continued use (Purdie and Boulton-Lewis, 2003; Sayago and Blat, 2009).

Older ICT users generally express a preference for human/social support over other forms such as accessing telephone helplines or online support. Sandhu, Damodaran and Ramondt (2013) found that with telephone helplines, some older users were unable to 'navigate' through the multi-step automated help menus necessary to reach a customer services advisor. Further there were complaints of not being able to get the right kind of support because automated systems or customer service advisors led them to the wrong department. Frustration with the process, often long-waiting times, and sometimes high associated costs appeared to be significant barriers to the use of help lines. Written documentation also posed problems e.g. some users found manuals 'incomprehensible' while generic 'how to' books were found to offer limited assistance in solving technical problems. In addition, both such sources can quickly become outdated as technology moves on. The use of technical jargon was reported to be another source of confusion for the learner (Goodman, Syme and Eisma, 2003). Further, the sheer volume of information now available, especially on the internet poses an obstacle for many users - especially for older self-directed ICT users (Candy, 2004).

Poor memory and mild cognitive impairment make it likely that some older ICT learners/users will need explanations/instructions to be repeated frequently. However, older people report being embarrassed to ask class tutors the same questions repeatedly and this reluctance can become a barrier to learning. Gaining learning support from friends and peers is perceived as more empathetic and 'comfortable' and has the additional advantage of shared language and better understanding of the difficulties faced. The data suggests that such informal ICT support can be crucial in encouraging diffident older users to persist in their efforts with ICT use and in promoting confidence as well as capability.

Access to support from tutors is usually only available for the duration of a course or classes provided for older adult ICT users (Ramondt, Sandhu and Damodaran, 2013). For such reasons, short-term computer classes of finite duration are reported to be inadequate and unsatisfactory for many older people who seek continuing training and support to sustain their usage of technology (Xie, 2007). Some computer clubs or drop-in sessions in the community do provide such support on an ongoing basis, offering 'trouble-shooting' assistance to older ICT users faced with a problem. This is regarded by its users as a greatly valued service (Sandhu, Damodaran and Ramondt, 2013) and boosts capability and confidence. However, where such provision does exist, it is often under-funded, and provided on a partly or wholly voluntary basis which means opening hours can be very limited typically available for just a few hours per week. Such restricted access to assistance can mean major disruption in completing a task is caused by the long wait for help - an entire week in some cases (and considerably longer in some family situations). 
Other findings are that mixed ability classes or classes which cater for all ages are unsatisfactory for older adults' learning to use computers who report being 'left behind'(Mayhorn et al., 2004). The formality/informality of teaching style and format is also important to older learners. Formal training generally takes a conventionally recognized form and structure which is likely to be recognised, approved and validated. Typically it will follow a set, predefined process/protocol which is documented, certified and recognised by some form of qualification. As a consequence of such standardisation, it inevitably tends to lack flexibility which can pose difficulties for older people.

Informal teaching and learning by contrast is characterised by being responsive to needs and having a relaxed, friendly, or unofficial style, manner, or nature. It does not follow a set proscribed pattern but instead varies in style, format, tone to meet the needs of the individual learner and their situation/local need. Taylor, Rose and Wiyono (2004) found that older adults undertaking ICT training often preferred informal arrangements instead of a formalized and linear class structure. Informal learning in a community context (i.e. in a local familiar neighbourhood setting, with established social networks and whose members share a common interest) (Wellman, 2005) generally allows for a more relaxed pace of learning, more one-to-one guidance and support, interpersonal dialogue and interaction - and the results show that these attributes are sought and appreciated by older users.

Intergenerational learning in which young people (e.g. grandchildren, school pupils, college students) help older people to use ICTs and in exchange older people share some of their life experiences/skills are reported to have a positive impact on the older participants' selfefficacy (Meyer et al., 2002) and competency levels (McPake et al., 2005; Kenner et al., 2008). However this type of support is not without its disadvantages: it may not always to be available in a timely or appropriate way; some 'helpers' (especially grandchildren) tended to perform operating procedures too fast for the older learner to follow. As a consequence, although a presenting problem was solved or a specific task was accomplished, the older person had not learned how to do it themselves which meant that the capability to deal with the same issue when it next occurred did not develop (Sandhu, Damodaran and Ramondt, 2013). Xie (2007) found the biggest barrier faced by older people was the difficulty in getting technical support, especially from younger people who are reported to be impatient and have little time to provide explanations. Furthermore, it should be noted that the family and the household are entities that are subject to change and these changes will have profound influences for those who are part of it (Jessell, 2009). In other words, the support that family members provide may not always be available.

The brief review of the literature presented above indicates some of the digital inequalities associated with ICT support for older people. In the next section relevant findings from the Sus-IT project are presented to begin to fill the gap in knowledge and understanding regarding the role and function of ICT support in promoting digital participation. 


\section{Methodology}

\section{Research approach}

A key underpinning principle of the Sus-IT project was that the research should be participatory, i.e. involving and engaging with older people as active participants and coproducers of knowledge, rather than as passive subjects of the research. To reflect this principle, and to fulfil the objectives of the research, a range of data collection approaches and tools were designed with the aims of both generating quantitative and rich qualitative data, and enabling engagement with a wide and diverse sample of older people. To collect breadth and depth of data about older peoples' usage and experiences of digital technologies in general and computers and the internet in particular, the methods used included questionnaire-based surveys, individual interviews and observations, focus groups, case studies, and storytelling. Other aspects of the project (described elsewhere e.g.(Damodaran, Olphert and Sandhu, 2014) and therefore not reported here) involved and engaged older people in defining, developing and exploring potential solutions to the challenges of using digital technologies through workshops, co-design 'sandpits' and trials and evaluation of prototype technologies. The research approach and individual data collection tools were approved by the Ethical Committees of all the universities who took part in the project.

For consistency with the definitions used on New Dynamics of Ageing (NDA) programme, 'older people' were defined as those aged 50+. To reach older adults in all their diversity, the researchers worked collaboratively with individuals drawn from 33 existing groups/panels of older people in communities across the UK. These included:

- Age UK branches in Nottingham, Derby and Derbyshire, Leicester, Barnet, Guilford, Hackney and Guildford;;

- University of the Third Age groups in Long Eaton, Nottingham, Sutton Bonnington, Harrow and Ilkeston;

- Older peoples forums/panels in Ilkeston, Long Eaton, Enfield, Hackney and Chelmsford;

- Community groups and organisations in Nottingham, Erewash, Leicestershire, Royal Leamington Spa, Syresham, Hackney and Chelmsford

- Educational and learning establishments in Middlesex and Teeside in England and in Dundee, Arbroath, Forfar and Kirriemuir in Scotland ;

- Conferences and events including the Festival of Social Sciences Event, Cotmanhay and the 'Taming the Dragon' workshop held in Chelmsford.

In total more than 1000 older people have participated in one or more of the research activities during the course of the project. The relationship with the participants and groups was maintained and nurtured over the duration of the project, and a number of cases is ongoing.

\section{Methods and sample}

Findings reported in this paper derive from the mixed data collection activities used within a participatory research approach, as described above. Methods included in-depth interviews, 
focus groups, observation and storytelling techniques which were applied in the groups listed above. The protocols and schedules used were designed to investigate-the barriers to learning and to sustaining use of ICTs by older people. Details of the problem solving workshop used to produce a specification of user requirements for ICT support for older people (KT Equal, 2012).

- In-depth interviews

Twenty-one in depth interviews were held either face-to-face or in telephone discussions between an individual participant and a researcher, typically lasting between half to one hour, based around open-ended questions. Interviews were conducted to establish the motivations of learners for embarking on ICT learning and also to investigate their subsequent experiences, including the obstacles encountered (and ways of overcoming them) and sources of support. The age range of the interviewees ranged from 51 to 88 years of age. Interviews were conducted with volunteers drawn from two groups participating in the project:

(i) Teeside community centre located in the north-east of England: this centre offered IT learning sessions held once a week for three to four hours typically for 'terms' of about three months in duration. After a break activity re-starts with a different focus or topic. This programme of learning sessions became known as 'a club that does exploration and takes people beyond the IT norm'. The approach aims to promote more adventurous learning by trying new things, encouraging exploration, with a focus on making it relevant, having fun, and keeping it as a social process.

(ii) A computer class hosted by a national charity operating in the Midlands of England: Participants attended an eight week (two hours a week) introductory computer course in a formal classroom setting in a computer suite. The content of the course was structured with clear learning objectives and outcomes. The training was delivered by volunteers who typically were older adults themselves.

- Focus groups

Three focus groups were conducted with a total of twenty-eight older adults to explore the motivations of learners for embarking on ICT learning, to investigate their subsequent experiences, including the obstacles encountered such as the issues which caused frustration and difficulties with the technology, the coping strategies adapted and support accessed. In addition to addressing these topics, groups explored the issues that may be the trigger for some older people to give up using ICTs and their suggestions for potential support solutions to these problems. Focus groups were facilitated by a member of the Sus-IT research team and discussion sessions each lasted for approximately one and half hours. The age range of participants was between 50 and 80+. Focus groups were conducted in two locations: (i) the Midlands of England and (ii) Scotland.

(i) The Midlands: those who attended the focus groups in the Midlands were recruited from an informal voluntary group, staffed by volunteers who offer introductory courses 
on a weekly basis (two-hour session) and also provide support in learners' homes. The courses allow learners to learn in an informal setting and at their own pace.

(ii) Scotland: participants for the focus group in Scotland were recruited from the User Centre based at the University of Dundee. The User Centre offers four sessions a week, each of two hours duration. The centre has developed its own sense of community. It provides older people with an environment to learn at their own pace, in their own style, in an informal setting and where there is the opportunity to participate in research. Peer support as well as tutor support from university research staff is available as appropriate. Learners pay no fees per se, but are asked to make contributions.

\section{- Storytelling}

'Storytelling' was used to elicit accounts of the learning experiences of eight members of local community organisations in the midlands of England. At a community event aimed at promoting awareness of the benefits of digital inclusion and local online services, participants recounted in their own words how they had become 'digitally engaged' and described their motivations, achievements and the obstacles they encountered. The audience comprised older people, third sector service providers and representatives of local government. The age range of the participants was 50 to 76 .

\section{- Observations}

Over 28 hours of observations were made by researchers to document the issues that arose for older learners in the learning process. This offered insights into self-help and mutual support among older learners. The age range of the participants was 50 to 90 . Observations were conducted at three locations in the midlands of England who offered ICT learning and support for older people, including: (i) a national charity based in Leicester, Midlands, (ii) an Older People's Forum based in Derbyshire, Midlands and (iii) an informal voluntary community group based in Northamptonshire, Midlands.

(i) National charity based in Leicester, Midlands: this organisation provided an eight week (two hours a week) introductory computer course in a formal classroom setting. Ten one-hour observations were carried out. On average there were between seven and 12 participants in each group.

(ii) Older People's Forum based in Derbyshire, Midlands: this group offers introductory and intermediate courses as well as drop-in sessions for members on a weekly basis. The content of the introductory courses provided basic instruction on computer use. In the case of intermediary courses learners themselves select topics they wish to cover. Dropin sessions are available for ICT users at any level of proficiency to receive support, and assistance from tutors on any problems they maybe encountering outside of the classroom. Two one-hour drop-in sessions were observed. Six participants attended the first session and seven attended the second. The sessions appear to fulfil social as well as ICT-related needs since participants often choose to stay for the whole duration of the session although typically the problem they presented was solved within a few minutes. 
(iii) Informal voluntary community group based in Northamptonshire, Midlands: offered introductory courses on a weekly basis and informal support to learners in their own homes when required. Two one-hour sessions were observed. 18 participants attended each of the sessions.

- Problem solving workshops

Problem solving workshops were used to develop an effective model for ICT support for older people to enable them both to achieve and to sustain digital inclusion with the intention of using the output to inform design and provision of ICT support in the community. These workshops were carefully structured to allow for the sharing of knowledge, engagement in focused problem-solving and co-production of specific outputs. They began with information-sharing presentations to help set the context for the 'problem' and also provided an opportunity for participants to work in groups to review and refine statements of requirements and develop a forward plan through 'break-out' sessions. Each group was allocated a facilitator, who had participated in the planning process for the workshop (and through this preparatory process had gained detailed knowledge and sound understanding of the background and the strategic objectives of the workshop, and the crucial importance of thoroughly documenting the output). The stated objectives of the workshop were the following:

- to achieve a consensus on the characteristics of current ICT learning and support provision available to older people;

- to elicit a shared vision of the ICT learning and support provision sought by older people (and informed by their experiences and preferences);

- to formulate a strategy for transition from the current to the vision for future provision and a supporting "specification" for future learning and support delivery.

Invitations to the workshop were sent directly to 80 individuals and organisations who had indicated their interest in ICT learning and support and digital inclusion. The event was also publicised on the KT-Equal Consortium website. The 51 individuals who participated in the event included representatives from older people's interest groups (including third sector organisations); from a Government department, as well as a number of academics and practitioners.

The carefully tailored and facilitated workshop programme successfully enabled the objectives of the event to be met. The workshop provided documented outcomes (statements of user requirements; a user-generated strategy for sustainable ICT learning and support for older users of new technologies and a plan to achieve implementation) (Damodaran, Olphert and Sandhu, 2012).

\section{Data analysis}


the content of the twenty-one interviews, three focus group discussions and eight storytelling interviews were recorded verbatim and observation notes were written up by three researchers. The recordings were transcribed and the transcripts along with observation notes were then analysed using content analysis methods which allow for the interpretation of the content of data through the systematic classification process of coding and identifying themes or patterns (Hsieh and Shannon, 2005). To ensure inter-rater reliability of coding qualitative data, emerging themes were discussed by the three researchers to identify similarities and differences in the data.

\section{Results}

The collection and analysis of rich data on the collaborative anonymous project has provided extensive evidence that access and availability of human support is a prerequisite for successful and on-going digital engagement. Access to support is therefore a critical success factor (CSF) for effective digital participation and engagement. The results showing the crucial role of social context for ICT learning and support in reducing digital inequalities for older ICT users are presented below under three headings:

(i) The specification of older people's ICT support requirements elicited from participants in the problem solving workshop entitled "Taming the Dragon - making technology work for us," as described earlier and informed by Sus-IT research findings (KT Equal, 2012).

(ii) Identification of key attributes of effective ICT support (documented in data derived from interviews, focus groups, stories and observations) shown to be necessary to meet the stated requirements.

(iii) The collaborative development of the concept for the design of community-based ICT support provision to incorporate (i) and (ii) above. From the new knowledge gained from the research and extensive co-design activity and the collaboration of multiple stakeholders participating in the Sus-IT project as well as in the KT-Equal programme, an innovative output has been developed and published, namely, 'The Proposition: Community hubs Meeting older people's technology support needs, developing social communities and reducing isolation' (Damodaran and Olphert, 2013).

Each of these results are described in more detail below.

\section{Specification of older people's ICT support requirements}

The "Taming the Dragon - making technology work for us," workshop process elicited the following list of ICT support requirements (KT Equal, 2012):

- Readily available and from trusted sources

- Delivered in familiar and welcoming local venues across the UK that also offer opportunities to: 
- drop in for coffee

- meet friends

- escape the "angst" of digital participation at home alone

- Sustained and on-going (i.e. not 'one-off' initiatives, pilots, trials and projects).

- Embedded in social and purposeful activities.

- Free of formal assessment and 'pressure'.

- Help with problem-solving and troubleshooting e.g. upgrades, virus protection, setting up equipment, installing new software etc.

- Impartial information and advice about new devices, software, applications, accessibility aids etc.

- Opportunities to 'try-before-you-buy' and help with installation to ensure a smooth transition from existing set-ups.

- Opportunities to build on and extend existing skills and competence (without the need for formal classes or working towards formal qualifications).

\section{Key attributes of effective ICT support}

The research conducted on the Sus-IT project provides rich data both on the diverse individual needs and interests of older people and on their generic ICT support needs which need to be met if they are to be enabled to engage with digital technologies in a sustained way. Findings reveal the following key attributes characterise effective ICT support: usercentred; 'micro-learning' opportunities; support beyond the classroom; on-going 'troubleshooting' assistance and peer support and skills-sharing. Each of these attributes is described below.

\section{User-centred}

The findings show that focusing ICT skills development on purposeful and relevant activities directly related to the pursuit of passions and interests of older people (i.e. using ICT to enable them to do what matters to them) motivates them to participate in the digital world (which skills-based training often designed to increase employability of younger adults generally fails to do). Examples of strong interests of older people participating in the project included re-visiting the past in the virtual world e.g. viewing the geographical location of their childhood (sometimes the other side of the world in the case of older immigrants), finding websites relating to former military service, their comrades and war time experiences - and then making contact with former associates. Similarly, enabling and empowering people with ICT to pursue their interests in photography, cooking, craft and gardening (e.g. through learning how to download images taken with digital cameras, locating recipes, knitting and sewing patterns, gardening tips and linking with people who share their interests) has been shown to be a powerful motivator for gaining digital skills. Gaining information to understand and manage health conditions; making financial savings through internet purchasing were also identified as important drivers for digital participation.

Giving opportunities for users to influence the contents of the classes they attend is important in achieving a user-centred focus. This means older people at the grassroots level have a 
voice in the direction of the agenda and ongoing opportunities to fine-tune it. For instance, new cohorts of older learners attending a computer training course at a local library in the Midlands were consulted at the beginning of the course about what they would like to learn in the ensuing classes. The content of the next six weeks of the course was then structured around their interests and included how to engage in online communication, search for information, and research their family tree.

Creating the opportunity to learn in an experimental and playful manner was also found to capture the interests of older ICT users. Older people attending the computer classes/club in a community centre in Teeside (located in the north east of England) were encouraged to 'experiment', 'mess about' and 'play with' technologies to learn about the computer capabilities that were of particular interest to them. For instance, one participant explained that she had learnt about desktop publishing 'by playing about' on the computer at home following encouragement by the class tutor to do so and another discovered how to 'Skype' through "messing about" on her computer. These older learners felt sufficiently confident to 'play' and experiment with technologies because they knew that support was available to them beyond the classroom sessions, from the tutor and from their peers - a theme which will be discussed below. Importantly, they knew that if anything were to go wrong and they needed advice or assistance, they would be able to access that support in a timely manner.

\section{'Micro-learning' opportunities}

The approach adopted by an inspiring and pioneering tutor at the Teeside community centre allowed older ICT users to focus on what they chose to learn (as opposed to having to follow a fixed curriculum/lesson plan or being taught every function of a program which is often the case in generic computer classes typically focused on the acquisition of work-based skills and formal qualifications). This 'micro-learning' approach essentially allows participants to learn only what they feel they need to know for their immediate purposes. For instance, those who wanted to learn to use a computer in order to type their letters, were only interested in learning about the relevant word-processing functions - and not in spreadsheets or other standard components of many office-based training programs. In a focus group session discussing the approach, one participant commented that "there is no need to learn every function if there is not a specific need for it" and this view was endorsed by the other participants. This approach has been well received by older ICT users more widely and offers an effective method of learning for them which sustains their interest - and often leads to them extending their skills as they develop knowledge, expertise and confidence.

\section{Support beyond the classroom}

One of the common complaints voiced by older ICT users related to the lack of support available beyond the classroom sessions. This is also evidenced by Sus-IT data reported elsewhere (Sandhu, Damodaran and Ramondt, 2013; Damodaran, Olphert and Sandhu, 2014). Such support outside the classroom is especially important when new users are faced with difficulties such as remembering what they had learnt in the classroom or how to handle technical issues with their technological devices. Common problems include dealing with pop-ups, installation of upgrades and updates to software, Blue Screen messages, computer 
freezing, adjusting computer settings, getting two devices to work together e.g. printer and computer - or encountering something unknown.

Older ICT users who attended classes held, respectively, at the Teeside community centre and at a local village hall in the Midlands (run by an informal voluntary group) commented favourably on the supportive environment they experienced. Participants from both groups were unanimous in their appreciation of the support offered by the trainers and volunteers. Members of the group in Teeside were given the tutor's email address and felt comfortable in the knowledge that he did not mind them contacting him if they had a problem and they also knew from experience that he would respond promptly. Similarly, support beyond the classroom was also appreciated by those who attended the introductory classes in the Midlands. Confident in the knowledge that the trainers and volunteers were available to offer support alleviated the concerns and worries of participants about 'battling it alone' and reduced their worry and fear of doing something wrong, as the following comments reveal :

"We all have his email address. I have emailed him and he replies because he is always on his computer. Yes, if I have got a problem I can email him and he will tell me how to do it. (Interview, Teeside, P.5)

"The great thing about the trainers is that they are available whenever you need them. I feel bad about asking them, but if I got stuck with something outside the class, I know I can always call the trainers who will pop round and help me sort out the problem.” (Focus Group 2, Midlands, P16)

\section{On-going 'troubleshooting' assistance}

Older ICT users frequently need help to sustain their use of technology and to remain connected to the digital world. Documented observations at drop-in advice sessions offered by an Older People's Forum in the Midlands illustrated some of the wide array of problems which arise and which could potentially become serious obstacles to on-going ICT use unless or until resolved. For example, one person had unknowingly changed the settings on his computer and in doing so caused the windows and background to become black in colour and all the text to turn a bright green colour with the result that the user found it difficult to read the contents of the screen, compromising his ability to access email and cope with upgrades to the operating system of the device. Another situation which arises is where in the process of giving help with one issue, technical experts create inadvertently new problems for the non-expert user. For example, an assistant at a local computer store changed the icon for email on the tablet device brought in by an older person. This intervention left the user unable to access email. For addressing such difficulties and alleviating the associated frustration, drop-in sessions provide an invaluable source of support in helping people to overcome the technical problems that arise in ICT use and thus are key to enabling them to benefit from digital technologies.

\section{Peer support and skills-sharing}

Peer support (from volunteers) is routinely available at drop-in sessions at the Dundee User Centre as part of the service provided and at the beginners' courses and drop in sessions 
offered by the 50+ Forum in the Midlands. The findings showed a willingness on the part of many older ICT users - not just the recognised volunteers - in all the groups engaged with the project to helping others if they became 'stuck' and needed assistance. It was evident that peer support was greatly appreciated by participants. Older ICT users acknowledged the support they received from other members of the group. In one group a member explained how older ICT users could choose to work on their own if they preferred to do so, however that there was concern within the group for members who might be struggling or have memory problems. Older ICT users were comfortable with asking each other for help and sometimes found this was preferable to asking the trainer. Peer support often extended to outside the sessions/classes especially if difficulties were encountered or there were problems in remembering the content that was covered in class. General enthusiasm to learn from each other and to share their expertise, skills, discoveries and insights characterised the peer support process.

"We all have everybody's email address so like I was having a problem with something and I can't remember what it was now but I was having a problem and of course we all live within miles of each other, we don't go to each other's houses don't get me wrong, but we might see each other in street and say can I have that thing or what do I do with that it's like that". (Interview, Teeside, P.3)

'A culture has been fostered where people help people. Everyone in the group knows the rest of the group well and could contact and help each other if necessary.' (Focus Group 2, Midlands, P.8)

Findings also show that for some older ICT users drop-in sessions were important opportunities for social contact and they used the session time both to practice and extend their ICT skills and to socialise with peers - sometimes just dropping in 'for a coffee and a chat'.

\section{Concept for the design of community-based ICT support provision}

An important result of the research and associated co-design and collaborative development processes carried out by a wide range of stakeholders is the proposition that emerged for the design and delivery of ICT support in the community i.e. "The Proposition: Community hubs - Meeting older people's technology support needs, developing social communities and reducing isolation". The concept of a successful community hub are presented diagrammatically below 


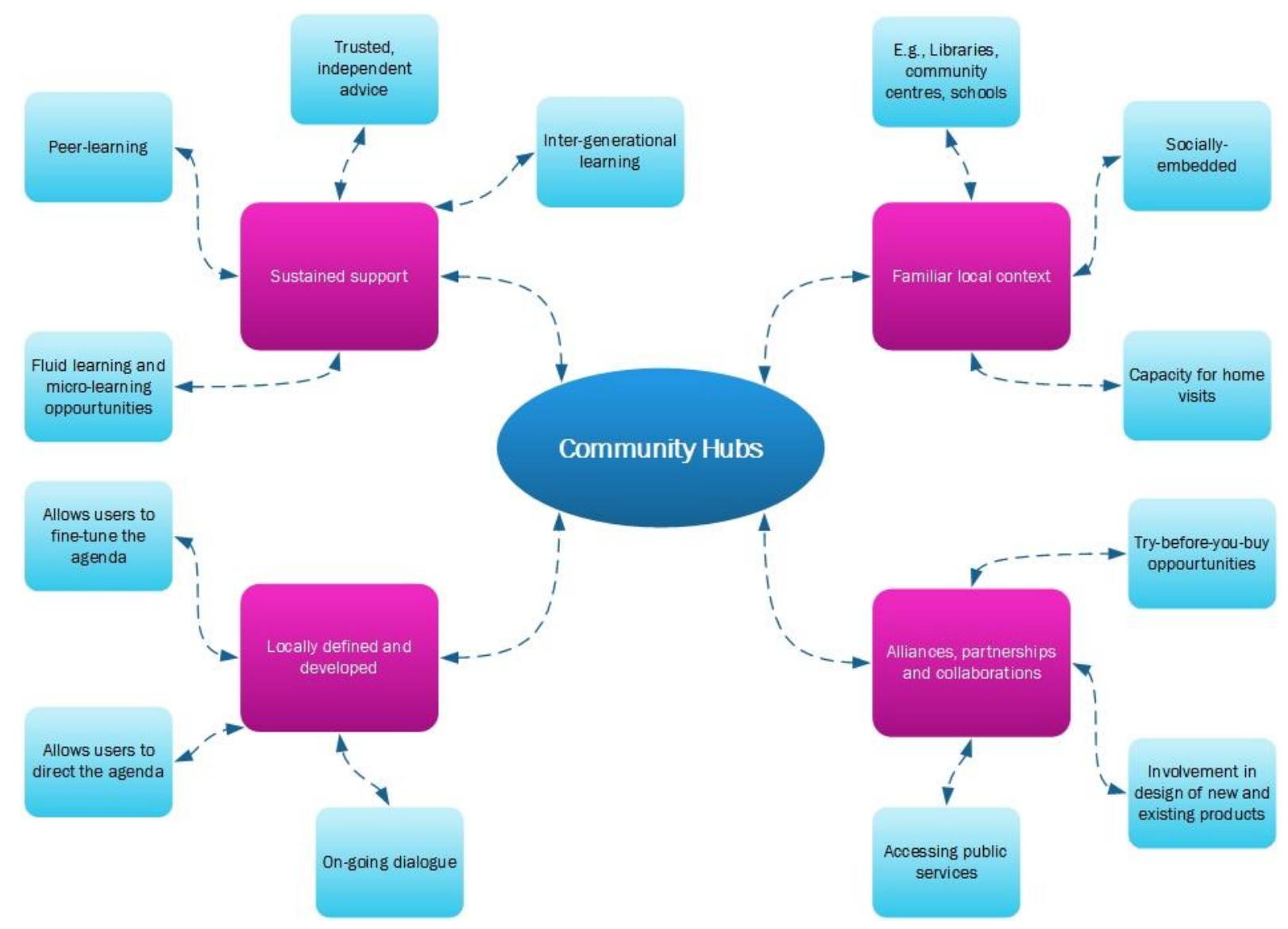

\section{Discussion and conclusions}

Findings reported in this paper show that social support has a crucial part to play in reducing digital inequalities for older ICT users. Learning to go online is only the beginning of the digital engagement journey and once the initial learning experience has passed, older users' new-found confidence can quickly be eroded when they encounter physical, psychological, social and technological barriers. Social support is shown to be key to reducing the impact these barriers have on older ICT users. A specification of support requirements and five key attributes of effective ICT learning and social support have been identified and described above. However, the evidence shows that the required support is generally in short supply in the UK. Findings of a study in seven UK cities revealed that ICT learning support provision (Ramondt, Sandhu and Damodaran, 2013) was extremely patchy and was variable in quality, availability, approach and content and falling a long way short of meeting the requirements specified by older people themselves. The study concluded that "the most serious deficiency identified is the low level of provision of help with 'troubleshooting' to address such matters as connection problems, choice of ISP, and the purchase of ICT devices".

The research findings cited in this paper strongly suggest that technological solutions alone cannot reduce digital inequalities sufficiently. Free Wi-Fi and access to ICT devices are essential but not sufficient for sustaining effective digital participation. Technological innovations such as tablet computers offer new and compelling ways to connect to the digital 
world and have undoubtedly helped many to 'get connected' who were previously defeated by the conventional configuration of computer, screen, keyboard and mouse. However, the frequently occurring technical changes such as 'upgrades' to operating systems are often experienced by older users as unwanted, unwelcome and threatening disruptions to on-going digital connection. Particularly frustrating and distressing for some is the perceived 'deskilling' effect of the changes often entailed in an upgrade as these make redundant the hardwon learned skills of users (often gained at great personal cost). To deal with such technical changes the older learner often requires access to assistance and support to learn afresh how to carry out tasks they had previously known how to do. Help is also often needed to learn how to carry out essential 'housekeeping' tasks such as deleting 'apps' and data to free up storage space which can baffle both the experienced and novice users.

It is the case that all but the very smallest employing organisations are likely to have ICT support personnel who will routinely deal with such issues. In addition, they can be expected to ensure, for example, that spam filters and virus checking software is installed and updated on a regular basis for employees and that training and support required by software upgrades is available. In sharp contrast, older people (and others) outside the workplace must fend for themselves or rely on formal or informal support mechanisms. The research findings reveal the rich and varied ways in which support is provided - in diverse permutations and combinations by friends, work colleagues, tutors, volunteers, peers, children, grandchildren or other family members. While these contributions and interventions clearly play a crucially important role in enabling older people to be part of the digital world, they fall a long way short of effective and satisfactory support for two important and over-arching reasons - first, not all older users have access to such support and second where it is available, its recipients often report shortcomings. The dearth of venues and mechanisms for older people to routinely access ICT support on a comparable scale and of a similar quality to that which is the norm in most workplaces, continues to be a serious shortcoming and a significant source of digital inequality. The point has already been made that despite the clear specification of their ICT support requirements articulated by older people, delivery of the required support is generally in short supply in the UK.

The implications of the research results suggest that for digital inequalities to be reduced significantly will require the development and delivery of sociotechnical solutions which will offer in an integrated systems approach, hardware and software that is 'user-friendly' in its capability to be adaptive and customized to individual needs and social and technical support that is affordable, sustainable, accessible to older people, both in the home and in the community on demand and on an on-going basis.

Also reported above are possible solutions to the serious deficiencies which exist in support provision. Ways of meeting the requirements articulated by users were explored in a coproduction process involving older people, practitioners and researchers (KT Equal, 2012). From this process, the concept of community-based ICT support emerged which has been developed into a detailed and well-informed proposition (Damodaran and Olphert, 2013). This proposition has been extensively deliberated with a range of key stakeholders in a consultation at St George's House (Damodaran, Olphert and Sandhu, 2012) and elsewhere. 
The underpinning premise of the proposition is that community-based ICT support provision enables older people to solve their problems, manage their lives (including their health conditions), enhance their well-being, engage with friends and pursue their passions empowered and enabled through their use of technology. The expectation, based on the evidence of small-scale local successes led by grass-roots organisations as well as by initiatives by local government, is that community-based support helps to create a positive learning experience, build confidence, promote well-being, prolong digital engagement and reduce the stresses and anxiety commonly associated with a lack of ICT support. Crucially, the evidence also suggests that enjoyment of a satisfying user experience with ICT is likely to encourage older people to progress to being 'digital by choice' in other areas of their lives including accessing government services on-line. Community-based support for ICT users will also assist in sustaining usage of ICTs by older people and will prevent or defer digital disengagement associated with ageing. By helping older people to develop digital skills of their choice, the community ICT support venues will also facilitate access to the wide range of social, healthcare, economic and other benefits that being online can deliver and, through such processes, promote autonomy and independence. Through this capacity to promote inclusion and to reduce social isolation, community-based ICT support can be expected to ease the scale of demand that older people make on other support systems.

To achieve sustainability, innovative funding models and revenue streams will be an essential part of any viable blueprint for widespread implementation of community-based ICT support provision across the UK. Many stakeholders identified in the proposition documents will have business interests which would be served by investing in the implementation of community-based ICT support. Banks, retailers (such as supermarkets and mobile phone/computer companies), product developers, local and central government and many others will all benefit from having more people competent and confident operating on-line. Setting up appropriate community-based support offers a way of achieving the objective of greater digital participation across society. It also has the potential to benefit such businesses by providing a platform for retailers and service providers to demonstrate their online services, provide information and support, build capability in the older population, encourage customer loyalty and develop user engagement. Additionally, community-based support will provide opportunities for hardware, software and web accessibility designers to evaluate older users' needs and preferences, and to trial and test prototypes and products. In turn this will enable better targeting and improved design of products and services that appeal to the older market and meet the real needs of older people. The vast potential of the communitysupport proposition has yet to be fully recognized but it has informed an ambitious local government initiative in Scarborough in the UK. This plan can be expected to reduce digital inequalities for its older citizens while meeting the council's objective of increasing uptake of on-line services by this group and of promoting self-care. This development suggests that the role of ICT support in the community in empowering citizens to participate in the digital world is beginning to be recognized as a strategic priority, encouraging the implementation of the proposition on a wider scale, reducing digital inequalities and moving towards the vision of widespread digital inclusion. 
Keywords: digital inclusion; digital inequality; older people; social support; learning and support, ICT.

\section{References}

- Blake, M. (2004) Internet access for older people. ASLIB Proceedings, No 50, pp.30815.

- Candy, P.C. (2004). Self-directed learning in the digital age. Australian Government Department of Education, Science and Training. [online] http://www.dest.gov.au/NR/rdonlyres/5CBAC2EE-D568-4829-83320739057BBE1B/2205/report.pdf (accessed on 25th May 2011).

- Damodaran L., Olphert, C.W. and Sandhu J. (2012) Falling off the Bandwagon? Sustaining Digital Engagement by Older People. Consultation Report. [online] http://www.stgeorgeshouse.org/index.php/download_file/481/226/

- Damodaran, L. and Olphert, C. W. (2013) The proposition - community hubs: meeting older people's technology support needs, developing social communities and reducing isolation, [online] http://sus-it.lboro.ac.uk/SusIT_KT_HubsOct13.pdf

- Damodaran, L., Olphert, C.W., Sandhu, J. (2014) 'Falling off the Bandwagon? Exploring the factors that can lead to digital disengagement by older people.' Gerontology, No. 60, pp.163-173

- $\quad$ Dickinson, A., Eisma, R., Gregor, P., Syme, A., and Milne, S. (2007) 'Strategies for teaching older people to use the world wide web'. Universal Access in the Information Society, No 1, pp.3-15.

- Digital Inclusion Panel. 2004. Enabling a Digitally United Kingdom: A Framework for Action, Cabinet Office, London.

- Dutton W H, Blank G.(2011) Next Generation Users, The Internet in Britain. Oxford Internet Survey 2011. Oxford, Oxford Internet Institute, University of Oxford.

- Echt, K. V. (2002) 'Designing web-based health information for older adults: visual considerations and design directives'. In Older Adults, Health Information and the World Wide Web. Eds. Morrell, R.; W. Lawrence Erlbaum Associates: New Jersey, pp.61-87.

- Emmanouilides, C. and Hammond, K. (2000) 'Internet usage, predictors of active users and frequency of use.' Journal of Interactive Marketing, No. 2, pp.17-32.

- Goodman, J., Syme, A. and Eisma, R. (2003) 'Older adults' use of computers: a survey.' In Proceedings of British HCI Group Annual Conference Bath, UK, September 2003. Springer-Verlag, London.

- Gorard, S and Selwyn, N. (2005) 'Towards a le@ @ning society? the impact of technology on patterns of participation in lifelong learning', British Journal of Sociology of Education, No1, pp.71- 89

- Hawthorn, R. (2008) ICT and the over 50s: overcoming barriers to employment and training advice. [online] www.crac.org.uk/CMS/files/upload/nicec_ict_over_fifties.pdf (accessed 13th December 2012). 
- Hsieh, H.F. and Shannon, S.E. (2005) Three approaches to qualitative content analysis. Qualitative Health Research, No.15, pp.1277-1288.

- Jessell, J. (2009) Family structures and intergenerational transfers of learning: changes and challenges. London: DFES, HMSO

- Katz J. E., Apsden, P. 1998. 'Internet dropouts in the USA, the invisible group. Telecommunications Policy.' No. 22, pp.327-339.

- Kenner, C., Ruby, M., Jessel, J., Gregory, E. and Arju, T. (2008) 'Intergenerational learning events around the computer: a site for linguistic and cultural exchange.' Language and Education, No 4, pp. 298-319

- $\quad$ KT- Equal. (2012) Monograph: Taming the Dragon - making technology work for us. KT Equal, University of Bath. [online] http://ktequal.org.uk/uploads/monograph\%20taming\%20the\%20dragon\%20final.pdf (accessed 30th April 2012).

- Mayhorn, C.B., Stronge, A.J., McLaughlin, A.C., \& Rogers, W.A. (2004) 'Older adults, computer training, and the systems approach: A formula for success'. Educational Gerontology, Vol. 3 No 1, pp.85-203.

- $\quad$ McPake, J., Stephen, C., Plowman, L., Sime, D. and Downey, S. (2005) 'Already at a disadvantage? ICT in the home and children's preparation for primary school ICT Research Bursary 2003-04 Final Report'. Institute of Education, University of Stirling, Becta.

- $\quad$ Meyer, B. J. F., Middlemiss, W., Theodorou, E., Brezinski, K. L., McDougall, J., and Bartlett, B. J. (2002) 'Effects of structure strategy instruction delivered to fifth grade children using the Internet with and without the aid of older adult tutors.' Journal of Educational Psychology, No. 3, pp.486-519.

- Ofcom. (2009) Digital Lifestyles, Media Literacy Audit, Research Document, United Kingdom.

- Office for National Statistics. [online] http://www.ons.gov.uk/ons/rel/rdit2/internetaccess-quarterly-update/index.html (accessed on 22 ${ }^{\text {nd }}$ June 2014)

- Office for National Statistics. [online] http://www.statistics.gov.uk/hub/population/ageing/older-people (accessed on $22^{\text {nd }}$ June 2014)

- $\quad$ Olphert, C. W. \& Damodaran, L. (2013) 'Digital disengagement and older people: the fourth digital divide?' Gerontology, Vol. 201 No 6, pp.564-70

- Purdie, N. and Boulton-Lewis, G. (2003) 'The learning needs of older adults.' Educational Gerontology, No 2, pp.129 - 35.

- Ramondt, L., Sandhu, J. and Damodaran, L. (2013) 'Staying digitally connected - a review of current learning and support provision in seven cities for older people.' International Journal of Education and Ageing, No. 2, pp.95-114

- Sandhu, J., Damodaran, L. \& Ramondt, L. (2013) 'ICT Skills Acquisition by Older People: Motivations for learning and barriers to progression.' International Journal of Education and Ageing, No. 1, pp.25-42

- Sayago, S. and Blat, J. (2009) About the relevance of accessibility barriers in the everyday interactions of older people with the web, Proceedings of International Cross- 
disciplinary Conference on Web Accessibility (W4A-ACM), Madrid, Spain, April 20-21 2009, ACM.

- Schieber, F. (2003) 'Human factors and aging: Identifying and compensating for age related deficits in sensory and cognitive function'. In Impact of technology on successful aging, Eds. K. W. Schaie \& N. Charness, Springer, New York, USA, pp.85-99.

- Selwyn, N. (2003) 'ICT for all?' Access and use of public ICT Sites in the UK'. Information, Communication \& Society. Vol 6, No 3, pp.350-375

- Selwyn, N. (2004) 'The Information aged: A qualitative study of older adults' use of information and communications technology', Journal of Ageing Studies, No.18, pp.369384

- $\quad$ Taylor, T., Rose, J., \& Wiyono, A. (2004) 'Older learners and ICT: Strategies and case studies.' Canberra: Australian Department of Education, Science and Training.

- Virokannas, H., Rahkonen, M., Luoma, I. and Sorvari, M. (2000) 'The 60-year-old female worker as user of new technology'. International Journal of Industrial Ergonomics, No 5, pp.491-5.

- Wellman, B. (2005) Community: from neighborhood to network. Communications of the ACM, 48(10), pp.53-55.

- Williamson, K., Bow, A., Wale, K. (1997) Breaking Down the Barriers to Public Internet Access. Proceedings of the International Conference of Computer Communication and International Telecommunications Society joint conference, Calgary, Alberta, Canada.

- Xie, B. (2007) 'Information Technology Education for Older Adults as a Continuing Peer-Learning Process: A Chinese Case Study', Educational Gerontology, No. 5, pp.429- 450.

- Young, W., Klima, G., Gadag, V., Gien, L. and Hardill, I. (2012) 'Sustaining Information and Communication Technology use among Canadians with at Least One Activity Limitation'. The International Journal of Technology, Knowledge and Society, No. 1, pp.1-12. 